Meta

Journal des traducteurs

Translators' Journal

\title{
Translating and the Computer
}

\section{Jean-François Grégoire}

Volume 25, numéro 3, septembre 1980

URI : https://id.erudit.org/iderudit/002966ar

DOI : https://doi.org/10.7202/002966ar

Aller au sommaire du numéro

Éditeur(s)

Les Presses de l'Université de Montréal

ISSN

0026-0452 (imprimé)

1492-1421 (numérique)

Découvrir la revue

Citer cet article

Grégoire, J.-F. (1980). Translating and the Computer. Meta, 25(3), 366-367.

https://doi.org/10.7202/002966ar

Ce document est protégé par la loi sur le droit d'auteur. L'utilisation des services d'Érudit (y compris la reproduction) est assujettie à sa politique d'utilisation que vous pouvez consulter en ligne.

https://apropos.erudit.org/fr/usagers/politique-dutilisation/
Cet article est diffusé et préservé par Érudit.

Érudit est un consortium interuniversitaire sans but lucratif composé de l'Université de Montréal, l'Université Laval et l'Université du Québec à Montréal. Il a pour mission la promotion et la valorisation de la recherche. https://www.erudit.org/fr/ 


\section{TRANSLATING AND THE COMPUTER}

Édité par Barbara M. Snell, de la Rank Xerox, chez North-Holland Publishing Company. Ce sont les actes d'un séminaire organisé par le Technical Translation and Informatics Groups of Aslib, à Londres, le 14 novembre 1978.

Le titre aurait très bien pu être: «Translation and Information» ou même «Translators and Computer Specialists». Parce que le sujet était bien l'informatique au service de la traduction et que des représentants des deux disciplines étaient réunis pour en discuter.

La réunion a été de très courte durée. Seuls quelques-uns des projets européens de banques de terminologie, de traduction automatisée et de traduction aidée par ordinateur y ont été présentés; et les communications d'ordre général, ont apporté très peu de nouveau aux spécialistes à une exception près, celle qui présentait enfin le point de vue d'un traducteur qui n'était pas directement lié à un projet particulier... Enfin!

L'aspect le plus intéressant du colloque, si l'on considère la liste des participants, est la très forte proportion de traducteurs non spécialistes du sujet qui y ont assisté ; ils y ont certainement appris beaucoup et peut-être (les actes n'ayant rapporté ni les questions ni les discussions) s'y sont-ils aussi fait entendre.

Les actes eux-mêmes s'ajoutent à une bibliographie déjà longue et peuvent intéresser tout traducteur qui souhaite commencer à étudier ce domaine des applications de l'informatique à la traduction. Je me permets de les encourager vivement à le faire.

L'informatique peut accroitre considérablement l'efficacité du travail humain; elle peut aussi conduire à des réalisations essentielles qu'on ne pourrait envisager sans elle. Ainsi, toutes les disciplines sont appelées à s'en servir, qu'on le veuille ou non. Le processus d'informatisation doit être le plus humain et le moins douloureux possible. Pour cela, il est indispensable que ceux qui auront à utiliser l'informatique - et croyez bien que ce ne sont pas les informaticiens - se préparent sans délai à devenir des maîtres d'œuvre de la transfor- 
mation du travail quotidien de leur discipline. L'informatisation de la traduction ne doit pas être laissée aux mains des seuls informaticiens. Les traducteurs doivent être prêts à y prendre une part active. Les uns et les autres, j'en suis convaincu, peuvent s'entendre!

JeAn-François GréGoire 